\title{
A Novel Double Quad-Inverter Configuration for Multilevel Twelve-Phase Open-Winding Converter
}

\author{
Sanjeevikumar Padmanaban \\ Research \& Development, \\ Ohm Technologies, \\ Chennai, India. \\ sanjeevi_12@yahoo.co.in
}

Joseph Olorunfemi Ojo

Dept. of Electrical \& Computer Engg., Tennessee Technological University, USA.

Eskom Centre of Excellence in HVDC Engg., University of KwaZulu-Natal,

Durban, South Africa.

jojo@tntech.edu

\author{
Patrick William Wheeler \\ Power Electronics, Machines and Control Group \\ (PEMC), Dept. of Electrical \& Electronics Engg., \\ Nottingham University, UK. \\ pat.wheeler@nottingham.ac.uk \\ Pandav Kiran Maroti \\ Dept. of Electrical and Electronics Engg., \\ Marathwada Institute of Technology, \\ Aurangabad, India. \\ kiranpandav88@yahoo.co.in
}

\begin{abstract}
This paper work articulates the novel proposal of double quad-inverter configuration for multilevel twelvephase open-winding ac converter. Modular power units are developed from reconfigured eight classical three-phase voltage source inverters (VSIs). Each VSI has one additional bi-directional switching device (MOSFET/IGBT) per each phase and linked neutral with two capacitors. An original modified single carrier five-level modulation (MSCFM) algorithm is developed and modulates each 2-level VSIs as equivalent to ones 5-level multilevel inverter. Observed set of results are presented with model based numerical simulation software's (Matlab/PLECS) developments. Further, the results confirm the good agreement to the developed theoretical background. Proposed converter suits the need of lowvoltage/high-current applications such as ac tractions and 'More-Electric Aircraft' propulsion systems.
\end{abstract}

Keywords-Dual six-phase inverter, twelve-phase inverter, multilevel inverters, multiphase drives, multiple space vectors, pulse-width modulation.

\section{INTRODUCTION}

Multiphase ac drives technologies had proven the eminent solutions for limited rating (MOSFET/IGBT) device configurations. Benefits includes, reliability, redundant structure, limited dc link ripple, increased power density, fault tolerant, and reduced per-phase of inverter rating [1-7]. To exploit the above advantages, this article developed a twelve-phase (double quad or dual six-phase) multilevel inverter configuration for open-winding loads. Configured by two adjacent phases are spatially shifted by $30^{\circ}$ (symmetrical type) [1-6] or by $15^{0}$ (asymmetrical) [1-2, 7]. Advantage, feasibility to split the phases and driven by multiple standard VSIs as multiphase inverter [2-7]. Topologies are termed as dual-, triple-, quadruple and double quadruple three-phase ac drives and applicable to several low-voltage/high current ac traction and 'MoreElectric Aircraft' applications (MEA) [8-9]. Multiphase ac drives are applied as the replacement for the hydraulic and

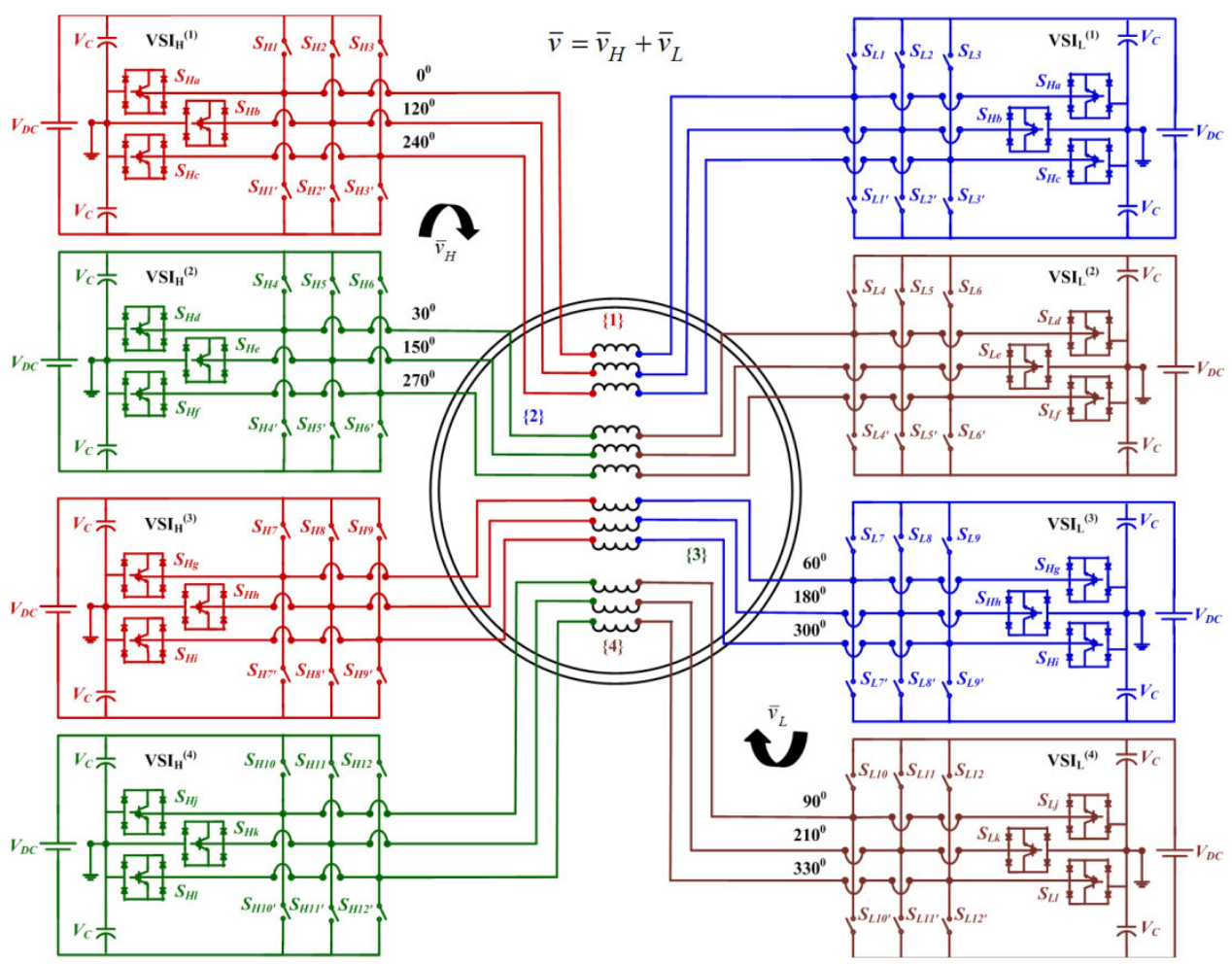

Fig. 1. Proposed configuration of quad-inverter system for symmetrical (twelve-phase) dual six-phase open-winding multilevel converter for medium power application (low-voltage/high-current). 
pneumatic actuators, highly reliable in fault conditions and improve overall aeronautic propulsion in MEA [9].

On other hand, the viability of ac drives are improved by the multilevel inverters (MLIs) for high voltage synthesis done by the sources and limited rating switching devices. Benefit by reduced total harmonic distortion (THD), and $\mathrm{dv} / \mathrm{dt}$ in the output voltages [10]. But potential vulnerability still persists in multilevel inverters, leading to total failure. Failures are occurred by the power parts (31-37.9) \% by the mechanism of IGBT devices for high-power applications [11]. Also, failures addressed with capacitors and gate control techniques [11-12]. Eventually, the combination of both multi-phase and multi-level inverter configuration becomes the solution for obtains high power ratings with limited rated devices [1, 3-7]. Still, the standard VSIs are reliable and reconfigured as both multi-phase and multilevel inverter by multiple VSIs proper arrangements [3-7]. Generally such topology referred as three-phase dual inverters, the two standard $3-\Phi$ VSI (two-level) are connected at each ends of the open-windings [3-6]. The potential difference across each phases of two single inverter's leg generates the multilevel output voltages when modulated 3-level VSIs. To be noted, dual inverters compromises the benefit of standard MLIs and commonmode currents are limited by the PWM strategies or by isolated dc sources [3-7]. All cases the dual inverters are restricted with output voltage levels, each leg are limited to three-levels. [1-7].

Motivation is set to above facts; in perspective view this paper work articulates a novel configuration for dual sixphase (double quad or twelve-phase) symmetrical/ asymmetrical multilevel converter as shown in Fig. 1 [3-7]. Topology fits star-winding/open-winding loads, lowvoltage/high-current medium power and 'MEA' applications. Also, this work developed an original modified single carrier five-level modulation (MSCFM) scheme (independent modulation for each VSI) and generates 5level outputs [13]. Modular converter consist of eight classical three-phase voltage source inverters (VSIs $\mathrm{H}$ and L) with one bi-directional (IGBT) switch per each phases and each VSIs is connected across each ends of openwindings [3-6]. Linked to the two capacitors with neutral connection with $\mathrm{VSI}_{\mathrm{H}}{ }^{(1)}, \mathrm{VSI}_{\mathrm{L}}{ }^{(1)}, \mathrm{VSI}_{\mathrm{H}}{ }^{(2)}, \mathrm{VSI}_{\mathrm{L}}{ }^{(2)}, \mathrm{VSI}_{\mathrm{H}}{ }^{(3)}$, $\mathrm{VSI}_{\mathrm{L}}{ }^{(3)}, \mathrm{VSI}_{\mathrm{H}}{ }^{(4)}$, and $\mathrm{VSI}_{\mathrm{L}}{ }^{(4)}$ for ensuring 5-level in each leg phases [13]. Since, all eight dc source are isolated and no circulation of homo-polar/zero-sequence currents [5]. The proposed converter holds redundant advantage that each VSI generates 5-level in their outputs irrespective of openwinding and/or star-winding structure. Overcomes the drawback of standard dual inverter topologies addressed in the literatures. Moreover, the total power among the eight dc sources and double quadrupling the power capabilities of each VSIs ( $\mathrm{H}$ and $\mathrm{L}$ ). Reliable under faulty condition one or two or three....VSIs fails and with single healthy VSI still propagates but with reduced power ratings. Also, compromised the standard MLIs benefits but with high reliability, easy to scale more than 12 -phases and redundant structure with fault tolerant $[6,10-12]$.

To verify the performances, the proposed symmetrical ac converter is numerical modelled with Matlab/PLECs simulation software's. Packages and tested under balanced conditions. Observed set of simulation results are presented in this paper version to show the effectiveness of the converter in symmetrical operating conditions and response shown always a close conformity with theoretical background.

\section{SPLIT-PHASE DECOMPOSITION SPACE VECTOR} TRANSFORMATION

The twelve-phase system can be represented by stationary rotating multiple space vectors as [1,3-7]:

$$
\begin{aligned}
& \bar{x}_{1}=\frac{1}{4}\left[\begin{array}{l}
x_{1}+x_{2} \alpha^{4}+x_{3} \alpha^{8}+x_{4} \alpha+ \\
x_{5} \alpha^{5}+x_{6} \alpha^{9}+x_{7} \alpha^{2}+x_{8} \alpha^{6}+ \\
x_{9} \alpha^{10}+x_{10} \alpha^{3}+x_{11} \alpha^{7}+x_{12} \alpha^{11}
\end{array}\right] \\
& \bar{x}_{3}=\frac{1}{4}\left[\left(\begin{array}{l}
x_{1}+x_{2}+x_{3}+ \\
x_{4}+x_{5}+x_{6}
\end{array}\right)+j\left(\begin{array}{l}
x_{7}+x_{8}+x_{9}+ \\
x_{10}+x_{11}+x_{12}
\end{array}\right)\right] \\
& \bar{x}_{5}=\frac{1}{4}\left[\begin{array}{l}
x_{1}+x_{2} \alpha^{8}+x_{3} \alpha^{4}+x_{4} \alpha^{5}+ \\
x_{5} \alpha^{9}+x_{6} \alpha^{13}+x_{7} \alpha^{10}+x_{8} \alpha^{14}+ \\
x_{9} \alpha^{18}+x_{10} \alpha^{15}+x_{11} \alpha^{19}+x_{12} \alpha^{23}
\end{array}\right] \\
& \bar{x}_{7}=\frac{1}{4}\left[\begin{array}{l}
x_{1}+x_{2} \alpha^{4}+x_{3} \alpha^{8}+x_{4} \alpha^{7}+ \\
x_{5} \alpha^{11}+x_{6} \alpha^{15}+x_{7} \alpha^{14}+x_{8} \alpha^{18}+ \\
x_{9} \alpha^{22}+x_{10} \alpha^{21}+x_{11} \alpha^{25}+x_{12} \alpha^{29}
\end{array}\right] \\
& \bar{x}_{9}=\frac{1}{4}\left[\left(\begin{array}{c}
x_{7}+x_{8}+x_{9}+ \\
x_{10}+x_{11}+x_{1 \jmath}
\end{array}\right)+j\left(\begin{array}{l}
x_{1}+x_{2}+x_{3}+ \\
x_{4}+x_{5}+x_{\kappa}
\end{array}\right)\right] \\
& \bar{x}_{11}=\frac{1}{4}\left[\begin{array}{l}
x_{1}+x_{2} \alpha^{8}+x_{3} \alpha^{4}+x_{4} \alpha^{11}+ \\
x_{5} \alpha^{15}+x_{6} \alpha^{19}+x_{7} \alpha^{22}+x_{8} \alpha^{26}+ \\
x_{9} \alpha^{30}+x_{10} \alpha^{33}+x_{11} \alpha^{37}+x_{12} \alpha^{41}
\end{array}\right]
\end{aligned}
$$

Where, $\alpha=\exp (j 2 \pi / 12)$, symmetrical converter version, displacement between windings [7]. The multiple space vectors $\bar{x}_{1}, \bar{x}_{5}, \bar{x}_{7}, \bar{x}_{11}$ are the four rotating vectors and $\bar{x}_{3}, \bar{x}_{9}$ are the zero sequence components. Exposed in the zones of $d_{1}-q_{1}, d_{5}-q_{5}, d_{7}-q_{7}, d_{11}-q_{11}$ and $d_{3}-q_{3}, d_{9}-q_{9}$ subspaces respectively. Now, to introduce split-phase space vector decomposition transformation to dual six-phase open-windings supplied by eight isolated dc source VSIs. The twelve-phase system can be split into four three-phase sub-systems $\{1\},\{2\},\{3\},\{4\}$ as [5-7]:

$$
\{1\}\left\{\begin{array}{l}
x_{1}^{(1)}=x_{1} \\
x_{2}^{(1)}=x_{2} \\
x_{3}^{(1)}=x_{3}
\end{array} ;\{2\}\left\{\begin{array}{l}
x_{1}^{(2)}=x_{4} \\
x_{2}^{(2)}=x_{5} \\
x_{3}^{(2)}=x_{6}
\end{array} ;\{3\} \quad\left\{\begin{array}{l}
x_{1}^{(3)}=x_{7} \\
x_{2}^{(3)}=x_{8} \\
x_{3}^{(3)}=x_{9}
\end{array} ;\{4\}\left\{\begin{array}{l}
x_{1}^{(4)}=x_{10} \\
x_{2}^{(4)}=x_{11} \\
x_{3}^{(4)}=x_{12}
\end{array} .\right.\right.\right.\right.
$$

The arbitrary rotating space vectors $\bar{x}^{(1)}, \bar{x}^{(2)}, \bar{x}^{(3)}, \bar{x}^{(4)}$ and the zero-sequence components $x_{0}^{(1)}, x_{0}^{(2)}, x_{0}^{(3)}, x_{0}^{(4)}$ are defined for four three-phase sub-system $\{1\},\{2\},\{3\}$ and $\{4\}$ as:

$$
\begin{aligned}
& \{1\}\left\{\begin{array}{l}
\bar{x}^{(1)}=\frac{2}{3}\left[x_{1}^{(1)}+x_{2}^{(1)} \alpha^{4}+x_{3}^{(1)} \alpha^{8}\right] \\
x_{0}^{(1)}=\frac{1}{3}\left[x_{1}^{(1)}+x_{2}^{(1)}+x_{3}^{(1)}\right]
\end{array}\right. \\
& \{2\}\left\{\begin{array}{l}
\bar{x}^{(2)}=\frac{2}{3}\left[x_{1}^{(2)}+x_{2}^{(2)} \alpha^{4}+x_{3}^{(2)} \alpha^{8}\right] \\
x_{0}^{(2)}=\frac{1}{3}\left[x_{1}^{(2)}+x_{2}^{(2)}+x_{3}^{(2)}\right]
\end{array}\right.
\end{aligned}
$$




$$
\begin{aligned}
& \{3\}\left\{\begin{array}{l}
\bar{x}^{(3)}=\frac{2}{3}\left[x_{1}^{(3)}+x_{2}^{(3)} \alpha^{4}+x_{3}^{(3)} \alpha^{8}\right] \\
x_{0}^{(3)}=\frac{1}{3}\left[x_{1}^{(3)}+x_{2}^{(3)}+x_{3}^{(3)}\right]
\end{array}\right. \\
& \{4\}\left\{\begin{array}{l}
\bar{x}^{(4)}=\frac{2}{3}\left[x_{1}^{(4)}+x_{2}^{(4)} \alpha^{4}+x_{3}^{(4)} \alpha^{8}\right] \\
x_{0}^{(4)}=\frac{1}{3}\left[x_{1}^{(4)}+x_{2}^{(4)}+x_{3}^{(4)}\right]
\end{array}\right.
\end{aligned}
$$

Now, multiple space vectors and split-phase space vectors are related by substituting Eq. 3 and Eq. 2 in Eq. 1 and emphasized as below:

$$
\begin{aligned}
& \bar{x}_{1}=\frac{1}{4}\left[\bar{x}^{(1)}+\alpha \bar{x}^{(2)}+\alpha^{2} \bar{x}^{(3)}+\alpha^{3} \bar{x}^{(4)}\right] \\
& \bar{x}_{5}^{*}=\frac{1}{4}\left[\bar{x}^{(1)}+\alpha^{5} \bar{x}^{(2)}+\alpha^{10} \bar{x}^{(3)}+\alpha^{15} \bar{x}^{(4)}\right] . \\
& \bar{x}_{3}=x_{0}^{(1)}+x_{0}^{(2)}+j\left(x_{0}^{(3)}+x_{0}^{(4)}\right) \\
& \bar{x}_{7}=\frac{1}{4}\left[\bar{x}^{(1)}+\alpha^{7} \bar{x}^{(2)}+\alpha^{14} \bar{x}^{(3)}+\alpha^{21} \bar{x}^{(4)}\right] \\
& \bar{x}_{11}^{*}=\frac{1}{4}\left[\bar{x}^{(1)}+\alpha^{11} \bar{x}^{(2)}+\alpha^{22} \bar{x}^{(3)}+\alpha^{33} \bar{x}^{(4)}\right] \\
& \bar{x}_{9}=x_{0}^{(3)}+x_{0}^{(4)}+j\left(x_{0}^{(1)}+x_{0}^{(2)}\right)
\end{aligned}
$$

Inverse to Eq. 4 is given by:

$$
\begin{aligned}
& \{1\} \rightarrow\left\{\bar{x}^{(1)}=\bar{x}_{1}+\bar{x}_{5}^{*}+\bar{x}_{7}+\bar{x}_{11}^{*} ; x_{0}^{(1)}=\bar{x}_{3} \cdot 1\right. \\
& \{2\} \rightarrow\left\{\bar{x}^{(2)}=\bar{x}_{1} \alpha^{23}+\bar{x}_{5}^{*} \alpha^{5}+\bar{x}_{7} \alpha^{17}+\bar{x}_{11}^{*} \alpha^{11} ; x_{0}^{(2)}=\bar{x}_{3} \cdot j\right. \\
& \{3\} \rightarrow\left\{\bar{x}^{(3)}=\bar{x}_{1} \alpha^{2}+\bar{x}_{5}^{*} \alpha^{0}+\bar{x}_{7} \alpha^{10}+\bar{x}_{11}^{*} \alpha^{2} ; x_{0}^{(3)}=\bar{x}_{9} \cdot 1\right. \\
& \{4\} \rightarrow\left\{\bar{x}^{(4)}=\bar{x}_{1} \alpha^{21}+\bar{x}_{5}^{*} \alpha^{15}+\bar{x}_{7} \alpha^{3}+\bar{x}_{11}^{*} \alpha^{9} ; x_{0}^{(4)}=\bar{x}_{9} \cdot j\right.
\end{aligned}
$$

Noted, where the symbols "** and "."denote complex conjugate and scalar (dot) product, respectively.

\section{DOUBle QuAD-INVERTER SINGLE CARRIER BASED FIVE-LEVEL MODULATION ALGORITHM}

The $P$ total power of the dual six-phase inverter can expressed as the sum of power of the four three-phase windings $\{1\},\{2\},\{3\}$, and $\{4\}\left(\mathrm{VSI}_{\mathrm{H}}{ }^{(1)}, \mathrm{VSI}_{\mathrm{L}}{ }^{(1)}, \mathrm{VSI}_{\mathrm{H}}{ }^{(2)}\right.$, $\operatorname{VSI}_{\mathrm{L}}^{(2)}, \operatorname{VSI}_{\mathrm{H}}{ }^{(3)}, \operatorname{VSI}_{\mathrm{L}}{ }^{(3)}$, and $\left.\operatorname{VSI}_{\mathrm{H}}{ }^{(4)}, \operatorname{VSI}_{\mathrm{L}}{ }^{(4)}\right)[5]$ :

$$
\begin{gathered}
P=P^{(1)}+P^{(2)}+P^{(3)}+P^{(4)} \\
P=\frac{3}{2} \bar{v}^{(1)} \cdot \bar{i}^{(1)}+\frac{3}{2} \bar{v}^{(2)} \cdot \bar{i}^{(2)}+\frac{3}{2} \bar{v}^{(3)} \cdot \bar{i}^{(3)}+\frac{3}{2} \bar{v}^{(4)} \cdot \bar{i}^{(4)}
\end{gathered}
$$

By neglecting the bi-directional switch per phases and two capacitors with neutral point in the Fig. 1, results in four standard two-level inverters. Further, the modulations are carried out as like standard VSIs. By space vector theory, the output voltage vector $\bar{v}$ of the dual six-phase inverter can be expressed as the sum of the voltage vectors of four three-phase windings $\{1\}-\bar{v}^{(1)},\{2\}-\bar{v}^{(2)},\{3\}-\bar{v}^{(3)}$, and $\{4\}-\bar{v}^{(4)}$ by the eight three inverters $\left(\mathrm{VSI}_{\mathrm{H}}{ }^{(1)}, \mathrm{VSI}_{\mathrm{L}}{ }^{(1)}\right.$, $\left.\mathrm{VSI}_{\mathrm{H}}{ }^{(2)}, \operatorname{VSI}_{\mathrm{L}}{ }^{(2)}, \mathrm{VSI}_{\mathrm{H}}{ }^{(3)}, \mathrm{VSI}_{\mathrm{L}}{ }^{(3)}, \mathrm{VSI}_{\mathrm{H}}{ }^{(4)}, \mathrm{VSI}_{\mathrm{L}}{ }^{(4)}\right)$ and given below as [5-7]:

$$
\bar{v}=\bar{v}^{(1)}+\bar{v}^{(2)}+\bar{v}^{(3)}+\bar{v}^{(4)}
$$

By splitting twelve-phase windings into standard four threephase windings then Eq. 7 by considering Eq. 3 then the modulating vectors can represent for first-, second-, thirdand fourth three-phase windings as below:

$$
\begin{aligned}
& \bar{v}^{(1)}=\bar{v}_{H}^{(1)}+\bar{v}_{L}^{(1)} \\
& \bar{v}^{(2)}=\bar{v}_{H}^{(2)}+\bar{v}_{L}^{(2)} \\
& \bar{v}^{(3)}=\bar{v}_{H}^{(3)}+\bar{v}_{L}^{(3)} \\
& \bar{v}^{(4)}=\bar{v}_{H}^{(4)}+\bar{v}_{L}^{(4)}
\end{aligned}
$$

By considering Eq. 4, then Eq. 8 to Eq. 10 for inverters $\mathrm{VSI}_{\mathrm{H}}{ }^{(1)}, \mathrm{VSI}_{\mathrm{L}}{ }^{(1)}, \mathrm{VSI}_{\mathrm{H}}{ }^{(2)}, \mathrm{VSI}_{\mathrm{L}}{ }^{(2)}, \mathrm{VSI}_{\mathrm{H}}{ }^{(3)}, \mathrm{VSI}_{\mathrm{L}}{ }^{(3)}, \mathrm{VSI}_{\mathrm{H}}{ }^{(4)}$, $\mathrm{VSI}_{\mathrm{L}}{ }^{(4)}$, the modulating vectors can be expressed as:

$$
\begin{gathered}
\bar{v}_{H}^{(1)}=\frac{1}{3} V_{D C}\left(S_{H 1}+S_{H 2} e^{j 2 \pi / 3}+S_{H 3} e^{j 4 \pi / 3}\right) \\
\bar{v}_{L}^{(1)}=-\frac{1}{3} V_{D C}\left(S_{L 1}+S_{L 2} e^{j 2 \pi / 3}+S_{L 3} e^{j 4 \pi / 3}\right) \\
\bar{v}_{H}^{(2)}=\frac{1}{3} V_{D C}\left(S_{H 4} \alpha+S_{H 5} \alpha e^{j 2 \pi / 3}+S_{H 6} \alpha e^{j 4 \pi / 3}\right) \\
\bar{v}_{L}^{(2)}=-\frac{1}{3} V_{D C}\left(S_{L 4} \alpha+S_{L 5} \alpha e^{j 2 \pi / 3}+S_{L 6} \alpha e^{j 4 \pi / 3}\right) \\
\bar{v}_{H}^{(3)}=\frac{1}{3} V_{D C}\left(S_{H 7} \alpha^{2}+S_{H 8} \alpha^{2} e^{j 2 \pi / 3}+S_{H 9} \alpha^{2} e^{j 4 \pi / 3}\right) \\
\bar{v}_{L}^{(3)}=-\frac{1}{3} V_{D C}\left(S_{L 7} \alpha^{2}+S_{L 8} \alpha^{2} e^{j 2 \pi / 3}+S_{L 9} \alpha^{2} e^{j 4 \pi / 3}\right) \\
\bar{v}_{H}^{(4)}=\frac{1}{3} V_{D C}\left(S_{H 10} \alpha^{3}+S_{H 11} \alpha^{3} e^{j 2 \pi / 3}+S_{H 12} \alpha^{2} e^{j 4 \pi / 3}\right) \\
\bar{v}_{L}^{(4)}=-\frac{1}{3} V_{D C}\left(S_{L 10} \alpha^{3}+S_{L 11} \alpha^{3} e^{j 2 \pi / 3}+S_{L 12} \alpha^{3} e^{j 4 \pi / 3}\right)
\end{gathered}
$$

Now, by considering Eq. 12 to Eq. 15, the Eq. 8 the modulating vector of twelve-phase windings can be written as below:

$$
\begin{aligned}
\bar{v}= & \frac{1}{3} V_{D C}\left(\begin{array}{l}
S_{H 1}+S_{H 2} e^{j 2 \pi / 3}+S_{H 3} e^{j 4 \pi / 3}- \\
S_{L 1}+S_{L 2} e^{j 2 \pi / 3}+S_{L 3} e^{j 4 \pi / 3}
\end{array}\right)+ \\
& \frac{1}{3} V_{D C}\left(\begin{array}{l}
S_{H 4} \alpha+S_{H 5} \alpha e^{j 2 \pi / 3}+S_{H 6} \alpha e^{j 4 \pi / 3}- \\
S_{L 4} \alpha+S_{L 5} \alpha e^{j 2 \pi / 3}+S_{L 6} \alpha e^{j 4 \pi / 3}
\end{array}\right)+ \\
& \frac{1}{3} V_{D C}\left(\begin{array}{l}
S_{H 7^{2}}{ }^{2}+S_{H 8} \alpha^{2} e^{j 2 \pi / 3}+S_{H 9^{2}} e^{2} e^{j 4 \pi / 3}- \\
S_{L 7} \alpha^{2}+S_{L 8} \alpha^{2} e^{j 2 \pi / 3}+S_{L 9^{2}} \alpha^{2} e^{j 4 \pi / 3}
\end{array}\right)+ \\
& \frac{1}{3} V_{D C}\left(\begin{array}{l}
S_{H 10^{\alpha}} \alpha^{3}+S_{H 11} \alpha^{3} e^{j 2 \pi / 3}+S_{H 12} \alpha^{3} e^{j 4 \pi / 3}- \\
S_{L 10^{2}} \alpha^{3}+S_{L 11} \alpha^{3} e^{j 2 \pi / 3}+S_{L 12} \alpha^{3} e^{j 4 \pi / 3}
\end{array}\right)
\end{aligned}
$$

Therefore, now the arbitrary modulating vector for the dual six-phase inverter can be predicted by information of each single VSI [3-6]:

For single dual three-phase VSI $\left(\operatorname{VSI}_{\mathrm{H}}{ }^{(1)}\right.$ and $\operatorname{VSI}_{\mathrm{L}}{ }^{(1)}$ ), the switching states, upper-states are $\left\{S_{H}, S_{H 1}, S_{H 2}, S_{H 3}\right\}$, lowerstates are $\left\{S_{L}, S_{L 1}, S_{L 2}, S_{L 3}\right\}=\{1,0\}$ of the legs. Zerosequence currents are null, if assumed the system is balanced conditions, then Eq. 16 can be rewritten as eight separate three-phase VSIs. For the purposes of simplified investigation, the analyses on the proposed converter are performed with single carrier based 5-level modulation [13]. The modulating reference signals are compared against standard triangular carrier to provide maximum utilization of dc buses and ability to generate multilevel operation. 


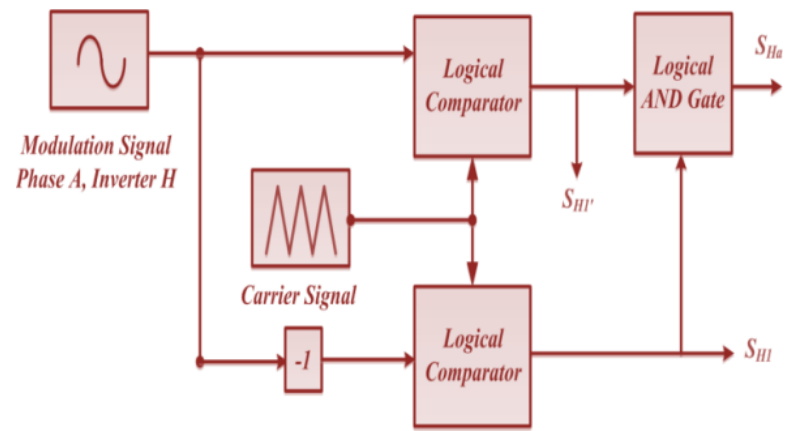

Fig. 2. Multilevel modulation scheme with one carrier for phase 'a' of inverter $\mathrm{VSI}_{\mathrm{H}}{ }^{(1)}$.

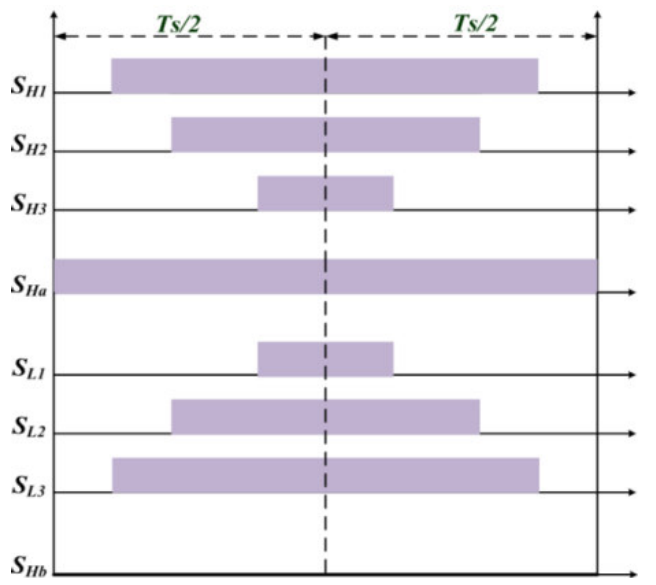

Fig. 3. PWM pattern of inverters $\mathrm{VSI}_{\mathrm{H}}{ }^{(1)}$ (top-three) and $\mathrm{VSI}_{\mathrm{L}}{ }^{(1)}$ (bottomthree) modulation Index $=0.8$ ).

Fig. 2 shows the single carrier (MSCFM) modulation algorithm for $\mathrm{VSI}_{\mathrm{H}}{ }^{(1)}$, and $\mathrm{VSI}_{\mathrm{L}}{ }^{(1)}$ generate 5-level across the leg-phase ' $a$ '. The same strategy is applied to all other legphases (b, c, d, e, f, g, h, i, j, k, l) of VSIs $\left(\operatorname{VSI}_{\mathrm{H}}{ }^{(2)}, \mathrm{VSI}_{\mathrm{L}}{ }^{(2)}\right.$, $\left.\mathrm{VSI}_{\mathrm{H}}{ }^{(3)}, \mathrm{VSI}_{\mathrm{L}}{ }^{(3)}, \mathrm{VSI}_{\mathrm{H}}{ }^{(4)}, \mathrm{VSI}_{\mathrm{L}}{ }^{(4)}\right)$. But note, keeping proper phase-shift between reference modulating signals as given by $\alpha=\exp (j 2 \pi / 12)$, symmetrical converter or $\alpha=\exp$ $(j \pi / 12)$, asymmetrical converter operation. For phase 'a', switch $S_{H a}$ and $S_{L a}$ to be modulated throughout the fundamental cycle, i.e. swaps between $\{1,0\}$ with switching cycle. Switch $S_{H 1}$ modulated half of the fundamental period (first-half) as $\mathrm{ON}$ and retains $\mathrm{OFF}$ second half. Applicable in reverse to the switch $S_{L 1}$ modulated half of the fundamental period (first-half) as OFF and retains ON second half. To be noted, same strategy is applied to other phases (b, c, d, e, f, g, h, I, j, k, l) to generate five-level outputs. A switch pattern of the proposed 5-level modulation for inverters $\operatorname{VSI}_{\mathrm{H}}{ }^{(1)}$ and $\mathrm{VSI}_{\mathrm{L}}{ }^{(1)}$ are shown in the Fig. 3 for the modulation index of 0.8 .

\section{NUMERICAL SIMULATION RESUlTS AND DisCUSSION}

TABLEI. MAIN PARAMETERS OF DUAL SiX-PHASE MULTILEVEL VSIS.

\begin{tabular}{ll|l}
\hline Dc Bus & $V_{D C}$ & $=200$ Volts \\
\hline Load Resistances & $R$ & $=8 \Omega$ \\
\hline Load Inductances & $L$ & $=10 \mathrm{mH}$ \\
\hline Fundamental Frequency & $F$ & $=50 \mathrm{~Hz}$ \\
\hline Switching Frequency & $F_{S}$ & $=5 \mathrm{KHz}$ \\
\hline Capacitors & $V_{C}$ & $=2200 \mu \mathrm{F}$ \\
\hline
\end{tabular}

Table I gives the elaboration of the parameters utilized for testing and to verify the effectiveness the complete symmetrical $(\alpha=\exp (j 2 \pi / 12))$ ac drive system is numerically developed in Matlab/PLECS simulation software package. The test conducted with balanced conditions by setting modulation index of eight $\mathrm{VSI}_{\mathrm{H}}{ }^{(1)}$, $\operatorname{VSI}_{\mathrm{L}}{ }^{(1)}, \operatorname{VSI}_{\mathrm{H}}{ }^{(2)}, \operatorname{VSI}_{\mathrm{L}}{ }^{(2)}, \operatorname{VSI}_{\mathrm{H}}{ }^{(3)}, \operatorname{VSI}_{\mathrm{L}}{ }^{(3)}, \operatorname{VSI}_{\mathrm{H}}^{(4)}, \operatorname{VSI}_{\mathrm{L}}{ }^{(4)}$ to 0.8 and overall modulation index of dual six-phase inverter is 0.8. Fig. 4 and Fig. 5 describe the complete behavior of the proposed multiphase converter system.

Fig. 4(A) and Fig. 4(B) are the generated line-line voltage of inverters $\mathrm{VSI}_{\mathrm{H}}{ }^{(1)}$ and $\mathrm{VSI}_{\mathrm{L}}{ }^{(1)}$, of first three-phase windings $\{1\}$. Fig. $4(\mathrm{G})$ and Fig. $4(\mathrm{H})$ are the generated line-line voltage of inverters $\mathrm{VSI}_{\mathrm{H}}{ }^{(2)}$ and $\mathrm{VSI}_{\mathrm{L}}{ }^{(2)}$, of second three-phase windings $\{2\}$. Correspondingly, depicted with its fundamental components and shown equal in amplitude and proven balanced operation. It is observed that they are out of phase with respect to each other VSIs $\mathrm{H}$ and $\mathrm{L}, 30^{\circ}$ spatial phase displacement between VSIs of first $\{1\}$ and second $\{2\}$ three-phase open-windings is observed and it is as expected. Further, confirms that each single VSIs are modulated in 5-level by the developed modified single carrier five-level modulation (MSCFM) algorithm. Hence, overcomes the drawback of addressed dual inverter configurations [3-6].

Fig. 4(C) and Fig. 4(D) are the artificially measured phase ' $a$ ' voltage of inverters $\operatorname{VSI}_{\mathrm{H}}{ }^{(1)}$ and $\mathrm{VSI}_{\mathrm{L}}{ }^{(1)}$, of first three-phase windings $\{1\}$. Fundamental components are depicted in the same figures and are in agreement to Eq. 12. Fig. 4(I) and Fig. 4(J) are the artificially calculated phase'd' voltage of inverters $\mathrm{VSI}_{\mathrm{H}}{ }^{(2)}$ and $\mathrm{VSI}_{\mathrm{L}}{ }^{(2)}$, of second threephase windings $\{2\}$. Fundamental components are depicted in the same figures and are in agreement to Eq. 13. It is observed that phase voltages of the VSI $\mathrm{H}$ and L are 7levels of stepped waveforms which are actually predicted. Further, it is verified that the phase voltages generated are of same amplitudes shown by fundamental components, and the balanced smooth operation is ensured (modulation index $=0.8$ ). It is observed that phase voltages are out of phase with respect to each other VSIs $\mathrm{H}$ and $\mathrm{L}, 30^{\circ}$ spatial phase displacement between VSIs of first $\{1\}$ and second $\{2\}$ three-phase open-windings is observed and it is as expected.

Fig. 4(E) and Fig. 4(K) are the generated phase voltage of the first three-phase open-winding (phase 'a') $\{1\}$ and the second three-phase open-winding (phase' $d$ ') $\{2\}$ along with its fundamental component. First, it is confirmed that the voltage generated are 7-levels in both open-windings $\{1\}$ and $\{2\}$. Obtained fundamental amplitude is the vector addition of phase voltages of inverters $\left(\mathrm{VSI}_{\mathrm{H}}{ }^{(1)}, \mathrm{VSI}_{\mathrm{L}}{ }^{(1)}\right)$ and $\left(\mathrm{VSI}_{\mathrm{H}}{ }^{(2)}, \mathrm{VSI}_{\mathrm{L}}{ }^{(2)}\right)$ and in agreement with Eq. 8 and Eq. 9. Second the fundamental components confirm, the phase voltages are equal in amplitude, $30^{\circ}$ spatial phase displacement is observed between voltages of openwindings $\{1\}$ and $\{2\}$. Hence balanced smooth propagation is ensured with dual six-phase converter with modulation index $=0.8$.

First three-phase $\{1\}$ and second three-phase $\{2\}$ openwinding currents are shown in Fig. 4(F) and Fig. 4(L). Generated currents are sinusoidal in nature, balanced with same amplitude with proper phase shifts of $30^{\circ}$ is observed between first three-phase windings $\{1\}$ and second threephase windings $\{2\}$. Conformity is shown by the proposed converter each VSIs are modulated sinusoidal in the openwindings $\{1\}$ and $\{2\}$, balanced conditions is propagated. Hence, the results discussed proven the requirement set by the theoretical developments for first and second threephase open-windings are in good agreement. 


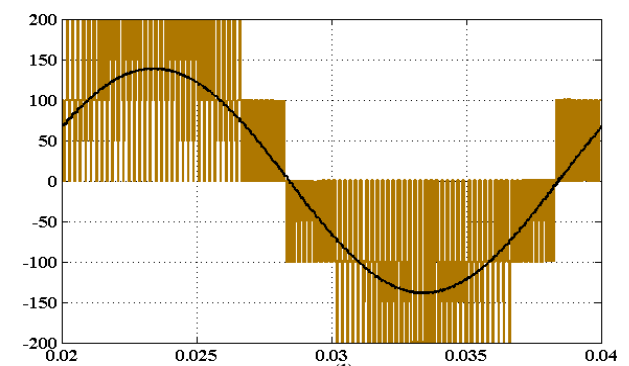

(A). Line-line voltage of inverter $\mathbf{V S I}_{\mathbf{H}}{ }^{(1)}$. [X-axis: Volt age, Y-axis: Time]

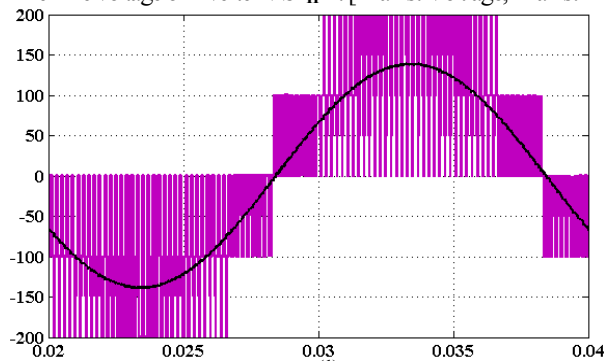

(B). Line-line voltage of inverter $\mathbf{V S I}_{\mathbf{L}}{ }^{(1)}$. [X-axis: Volt age, Y-axis: Time].

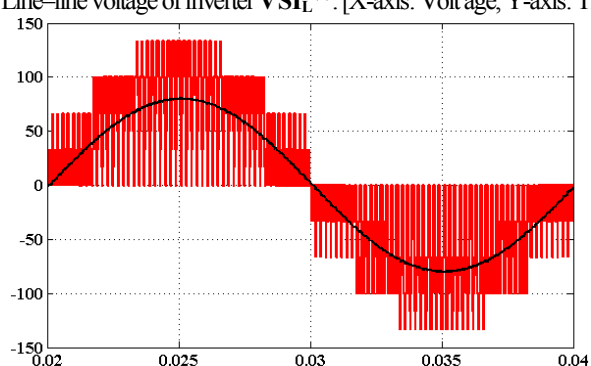

(C). Artificially first-phase voltage of inverters $\mathbf{V S I}_{\mathbf{H}}{ }^{(\mathbf{1})}$. [X-axis: Volt age, Y-axis: Time]

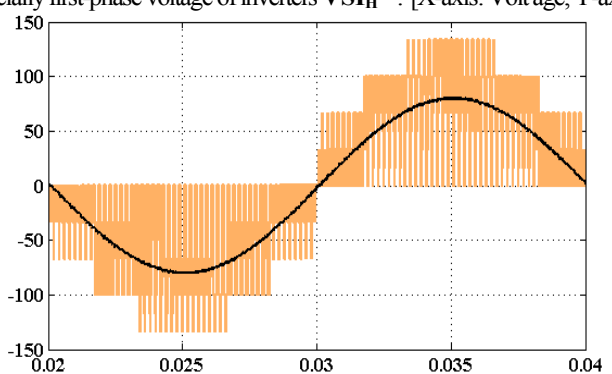

(D). Artificially first-phase voltage of inverters $\mathbf{V S I}_{\mathbf{L}}{ }^{(1)}$. [X-axis: Volt age, Y-axis: Time]

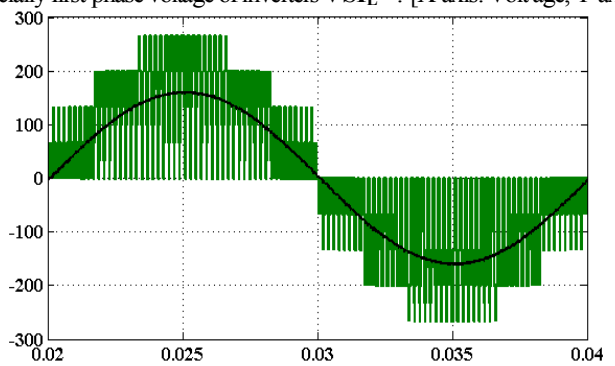

(E). First-phase voltage across the open-winding $\{1\}$. [X-axis: Volt age, Y-axis: Time].

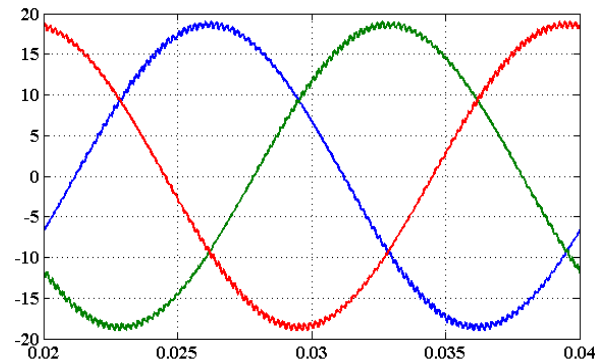

(F). First three-phase currents of the open-windings $\{1\}$. [X-axis: Current Y-axis: Time].

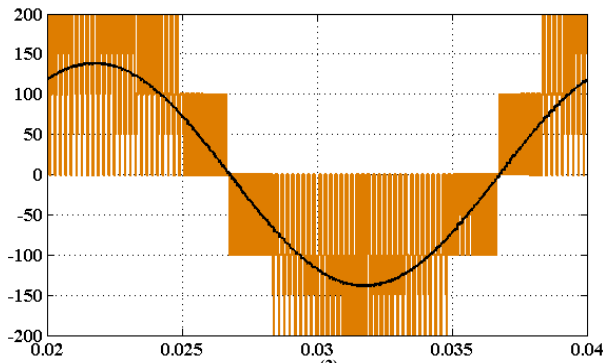

(G). Line-line voltage of inverter $\mathbf{V S I}_{\mathbf{H}}{ }^{(2)}$. [X-axis: Volt age, Y-axis: Time].

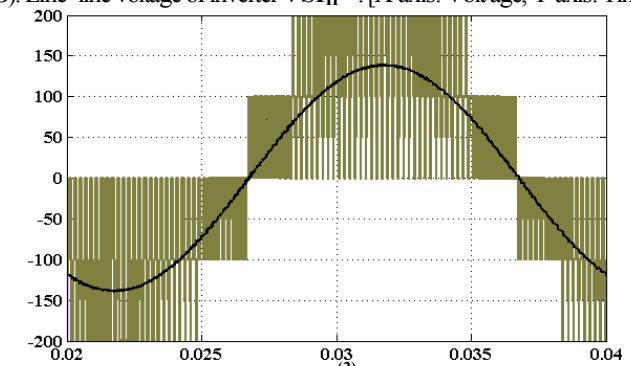

(H). Line-line voltage of inverter $\mathbf{V S I}_{\mathbf{L}}{ }^{(2)}$. [X-axis: Volt age, Y-axis: Time]

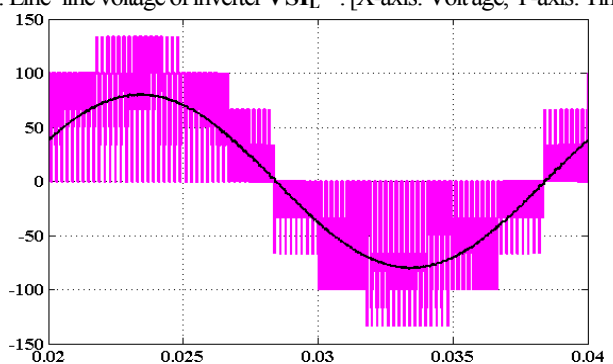

(I). Artificially first-phase voltage of inverters $\mathbf{V S I}_{\mathbf{H}}{ }^{(2)}$. [X-axis: Volt age, Y-axis: Time].

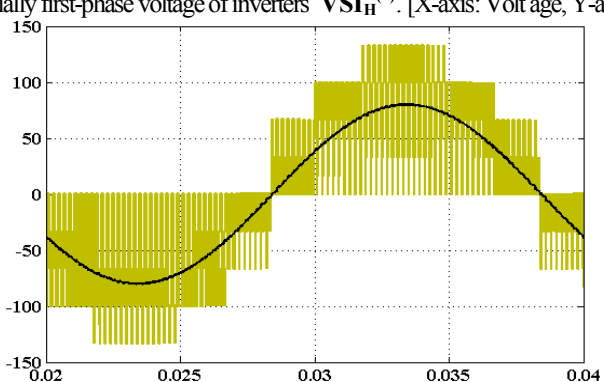

(J). Artificially first-phase voltage of inverters $\mathbf{V S I}_{\mathbf{L}}{ }^{(2)}$. [X-axis: Volt age, Y-axis: Time]

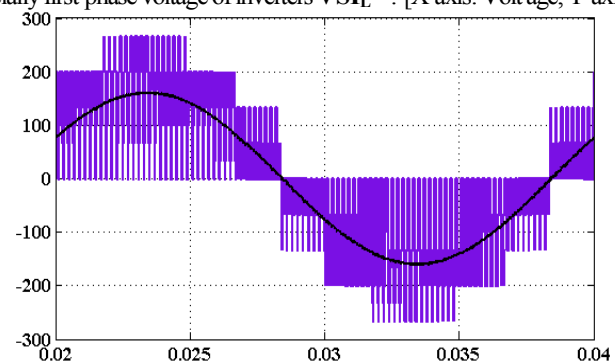

(K). Fourth-phase voltage across the open-winding $\{2\}$. [X-axis: Volt age, Y-axis: Time].

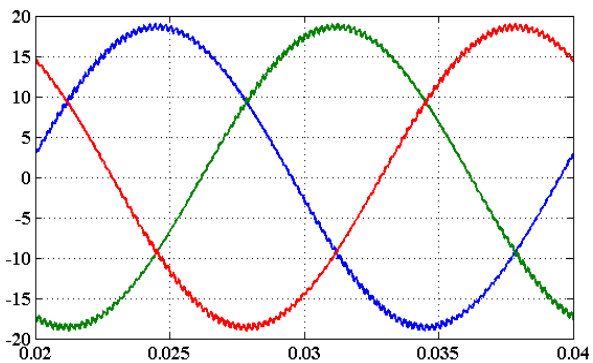

(L). Second three-phase currents of the open-windings $\{2\}$.

Fig. 4. Numerical simulation test behavior of the proposed multiphase-multilevel open-winding converter. Modulation index $=0.8$, kept for balanced operation. Voltages are depicted with its corresponding time averaged fundamental components. Left: First three-phase open-windings $\{1\}$. . Right: Second three-phase open-windings $\{2\}$. 


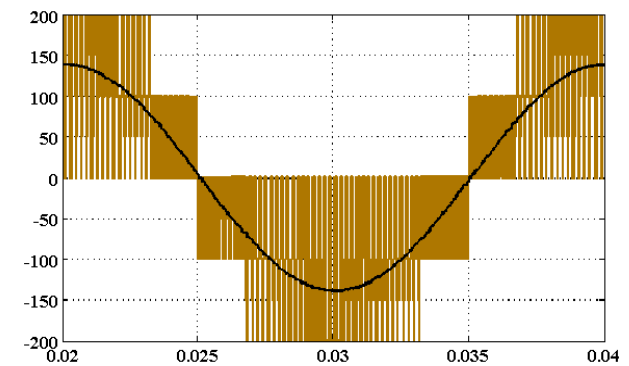

(A). Line-line voltage of inverter VSI ${ }_{\mathbf{H}}^{\left({ }^{3}\right)}$. [X-axis: Volt age, Y-axis: Time].

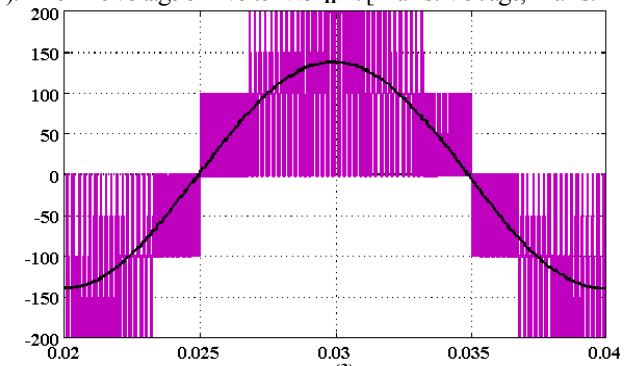

(B). Line-line voltage of inverter VSI $_{\mathbf{L}}{ }^{(3)}$. [X-axis: Volt age, Y-axis: Time]

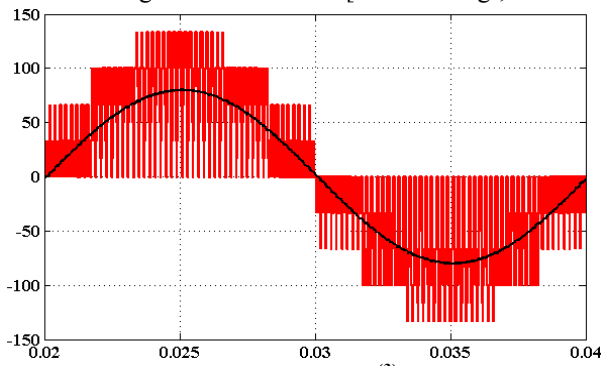

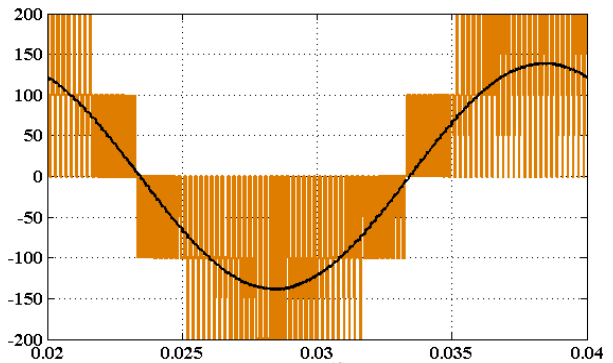

(G). Line-line voltage of inverter $\mathbf{V S I}_{\mathbf{H}}{ }^{(4)}$. [X-axis: Volt age, Y-axis: Time].

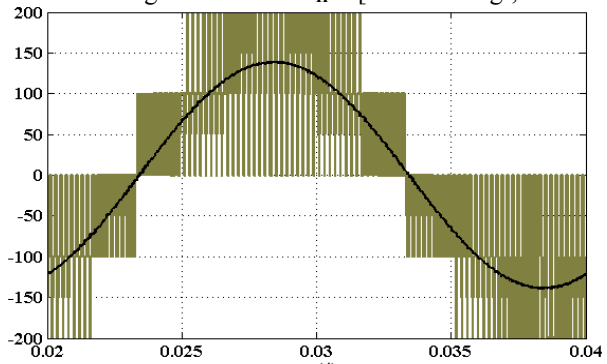

(H). Line-line voltage of inverter $\mathbf{V S I}_{\mathbf{L}}{ }^{(4)}$. [X-axis: Volt age, Y-axis: Time].

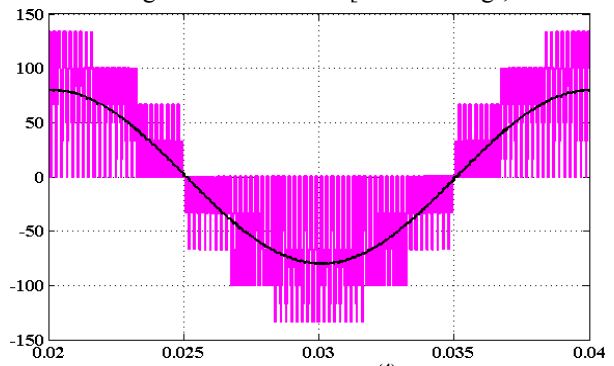

(C). Artificially first-phase voltage of inverters $\mathbf{V S I}_{\mathbf{H}}{ }^{(3)}$. [X-axis: Volt age, Y-axis: Time]. (I). Artificially first-phase voltage of inverters VSI ${ }_{\mathbf{H}}{ }^{(4)}$. [X-axis: Volt age, Y-axis: Time].
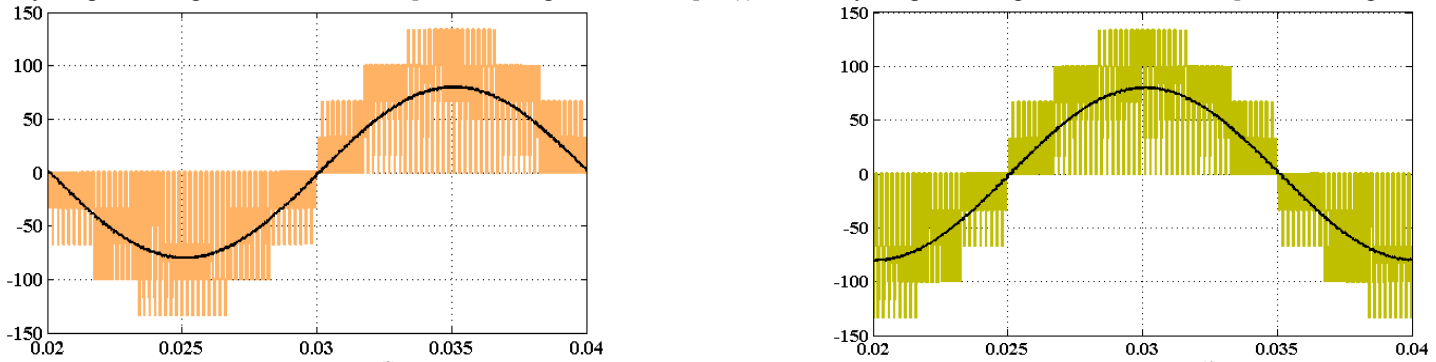

(D). Artificially first-phase voltage of inverters $\mathbf{V S I}_{\mathrm{L}}{ }^{(3)}$. [X-axis: Volt age, Y-axis: Time]. (J). Artificially first-phase voltage of inverters $\mathbf{V S S I}_{\mathrm{L}}{ }^{(4)}$. [X-axis: Volt age, ${ }^{0}$-axis: Time]
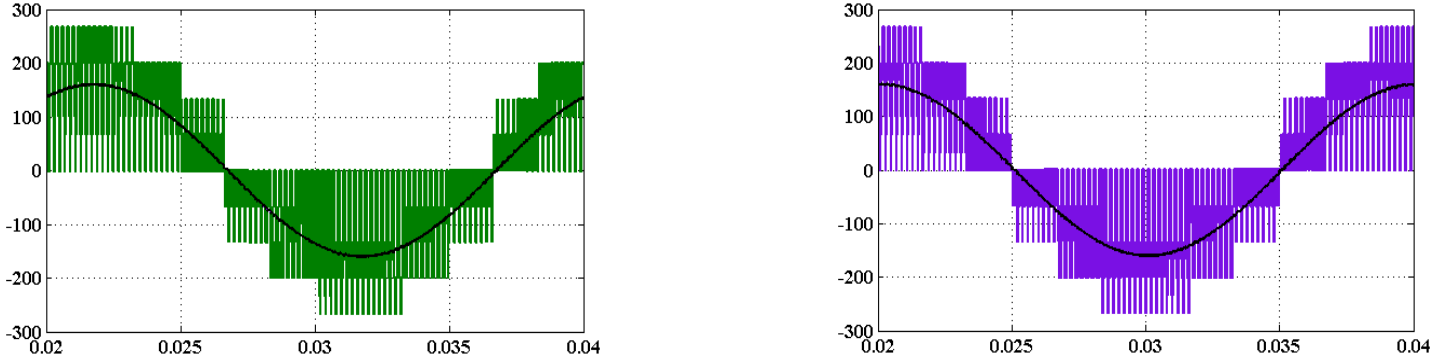

(E). Seventh-phase voltage across the open-winding $\{3\}$. [X-axis: Volt age, Y-axis: Time]. (K). Tenth-phase voltage across the open-winding $\{4\}$. [X-axis: Volt age, Y-axis: Time].

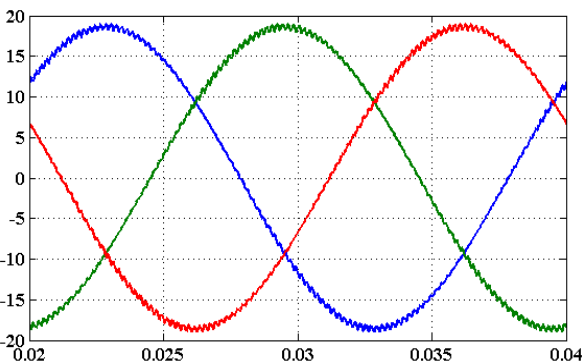

(F). Third three-phase currents of the open-windings $\{3\}$.

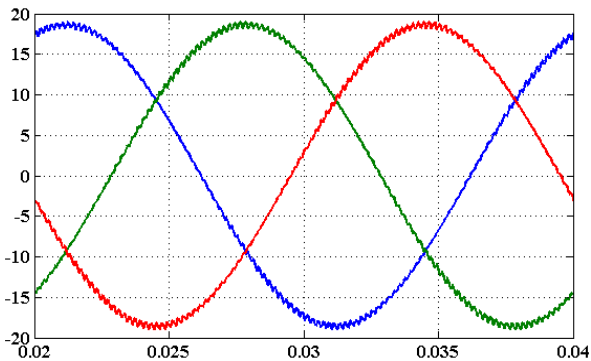

(L). Fourth three-phase currents of the open-windings $\{4\}$.

Fig. 5. Numerical simulation test behavior of the proposed multiphase-multilevel open-winding converter. Modulation index $=0.8$, kept for balanced operation. Voltages are depicted with its corresponding time averaged fundamental components. Left: Second three-phase open-windings $\{1\}$. . Right: Fourth three-phase open-windings $\{2\}$. 
Fig. 5(A) and Fig. 5(B) are the generated line-line voltage of inverters $\mathrm{VSI}_{\mathrm{H}}{ }^{(3)}$ and $\mathrm{VSI}_{\mathrm{L}}{ }^{(3)}$, of third three-phase windings $\{3\}$. Fig. $5(\mathrm{G})$ and Fig. $5(\mathrm{H})$ are the generated line-line voltage of inverters $\operatorname{VSI}_{\mathrm{H}}{ }^{(4)}$ and $\mathrm{VSI}_{\mathrm{L}}{ }^{(4)}$, of fourth three-phase windings $\{4\}$. Correspondingly, depicted with its fundamental components and shown equal in amplitude. Also, here it is observed that they are out of phase with respect to each other VSIs $H$ and $L, 30^{\circ}$ spatial phase displacement between VSIs of third $\{3\}$ and fourth $\{4\}$ three-phase open-windings is observed and it is as expected. Further, confirms that each single VSIs are modulated in 5level by the developed modified single carrier five-level modulation (MSCFM) algorithm. Hence, it is confirmed all the four three-phases are modulated in 5-level, with equal amplitude of fundamental components and proves balanced operation between all four VSIs.

Fig. 5(C) and Fig. 5(D) are the artificially measured phase ' $\mathrm{g}$ ' voltage of inverters $\mathrm{VSI}_{\mathrm{H}}{ }^{(3)}$ and $\mathrm{VSI}_{\mathrm{L}}{ }^{(3)}$, of third three-phase windings $\{3\}$. Fundamental components are depicted in the same figures and are in agreement to Eq. 14. Fig. 5(I) and Fig. 5(J) are the artificially calculated phase ' $\mathrm{j}$ ' voltage of inverters $\mathrm{VSI}_{\mathrm{H}}{ }^{(4)}$ and $\mathrm{VSI}_{\mathrm{L}}{ }^{(4)}$, of fourth threephase windings $\{4\}$. Fundamental components are depicted in the same figures and are in agreement to Eq. 15. Also, it is observed that phase voltages of the VSI H and L are 7levels of stepped waveforms which are actually predicted as like open-windings $\{1\}$ and $\{2\}$. Further, it is verified that the phase voltages generated are of same amplitudes shown by fundamental components, and the balanced smooth operation is ensured (modulation index $=0.8$ ). It is observed that phase voltages are out of phase with respect to each other VSIs $\mathrm{H}$ and $\mathrm{L}, 30^{\circ}$ spatial phase displacement between VSIs of third $\{3\}$ and fourth $\{4\}$ three-phase openwindings is observed and it is as expected like openwindings $\{1\}$ and $\{2\}$.

Fig. 5(E) and Fig. 5(K) are the generated phase voltage of the third three-phase open-winding (phase ' $\mathrm{g}$ ') $\{3\}$ and the second three-phase open-winding (phase ' $\mathrm{j}$ ') $\{4\}$ along with its fundamental component. First, it is confirmed that the voltage generated are 7-levels in both open-windings $\{3\}$ and $\{4\}$. Obtained fundamental amplitude is the vector addition of phase voltages of inverters $\left(\mathrm{VSI}_{\mathrm{H}}{ }^{(3)}, \mathrm{VSI}_{\mathrm{L}}{ }^{(3)}\right)$ and $\left(\mathrm{VSI}_{\mathrm{H}}{ }^{(4)}, \mathrm{VSI}_{\mathrm{L}}{ }^{(4)}\right)$ and in agreement with Eq. 10 and Eq. 11. Second the fundamental components confirm, the phase voltages are equal in amplitude, $30^{\circ}$ spatial phase displacement is observed between voltages of openwindings $\{3\}$ and $\{4\}$. Hence balanced smooth propagation is ensured with dual six-phase converter with modulation inde $x=0.8$ among all four windings.

Correspondingly, third three-phase $\{3\}$ and fourth threephase $\{4\}$ open-winding currents are shown in Fig. 5(F) and Fig. 3(L). As expected generated currents are sinusoidal in nature, balanced with same amplitude with proper phase shifts of $30^{\circ}$ is observed between third three-phase windings $\{3\}$ and fourth three-phase windings $\{4\}$. Conformity is shown by the proposed converter each VSIs are modulated sinusoidal in the open-windings $\{3\}$ and $\{4\}$, balanced conditions is propagated. Hence, the results discussed proven the requirement set by the theoretical developments for third and fourth three-phase open-windings are in good agreement. Finally, it is confirmed from the depicted test results that, the voltages and currents are spatially phase shifted by $30^{\circ}$ as expected between four three-phase windings. Hence the set proposal are verified and shown the double quad multilevel inverter is effective solution for low-voltage/high current applications.

\section{CONCLUSION}

A novel double quad (twelve-phase) multilevel inverter configured from the multiple standard three-phase VSI articulated by this paper work. An original modified single carrier five-level modulation (MSCFM) algorithm also developed. The PWM strategy modulates each single VSI $(\mathrm{H}$ and $\mathrm{L})$ as ones equivalent to 5-level outputs and compromises the benefit of standard multilevel inverters. Confirmatory results are obtained by numerical simulation software's modeling and shown with balanced power operations among eight isolated dc sources. Proposed multiphase-multilevel inverter effectively utilized for multiple batteries or fuel-cells fed system, for medium power, ac tractions and 'More-Electric Aircraft' (MEA) applications. Reliable under circumstances of asymmetrical available dc sources without affecting its multilevel operation subjected to quadrupling the power by eight VSI. Investigation is still kept under developments to frame a proper optimized multilevel (5-level) based on carrier based or space vector modulation PWM generation techniques for near future works.

\section{REFERENCES}

[1] E.Levi, R. Bojoi, F. Profumo, H.A. Toliyat, S. Williamson, "Multi $\neg$ phase induction motor drives - a technology status review," IET Electr. Power Appl., vol. 1, no.4, pp. 489-516, July 2007.

[2] G. Grandi, A. Tani, P. Sanjeevikumar, D. Ostojic, "Multi-phase multi-level ac motor drive based on four three-phase two-level inverters," Conf. Proc. IEEE Intl. $2^{\text {oth }}$ Symp, on Power Electron., Elect. Drives etc., IEEE-SPEEDAM'10, Pisa (Italy), pp. 1768-1775, 14-16 Jun. 2010.

[3] P.Sanjeevikumar, G.Grandi, Frede Blaabjerg, Patrick W.Wheeler, Olorunfemi Ojo, "Analysis and Implementation of Power Management and Control Strategy for Six-Phase Multilevel AC Drive System in Fault Condition", Engg. Science and Tech; An Intl. J. (JESTECH), Elsevier Pub., 13 Jul. 2015.

[4] G. Grandi, P. Sanjeevikumar, D. Ostojic, C. Rossi, "Quad-inverter configuration for multi-phase multi-level ac motor drives", Conf. Proc., Intl. Conf. Computational Technologies in Elect. and Electron. Engg., IEEE-SIBIRCON'10, Irkutsk Listvyanka (Russia), pp. 631638, 11-15 Jul. 2010.

[5] P.Sanjeevikumar, G.Grandi, Frede Blaabjerg, Joseph Olorunfemi Ojo, Patrick W.Wheeler, "Power Sharing Algorithm for Vector Controlled Six-Phase AC Motor with Four Customary Three-Phase Voltage Source Inverter Drive", Engg. Science and Tech; An Intl. J. (JESTECH), Elsevier Pub., vol. 16, no. 3, pp. 405-415, 11 Feb. 2015.

[6] G. Grandi, P. Sanjeevikumar, Y. Gritli, F. Filippetti, "Experimental investigation of fault-tolerant control strategies for quad-inverter converters", Conf. Proc. IEEE Intl. Conf. on Electrical System for Aircraft, Railway and Ship Propulsion, IEEE-ESARS'12, Bologna (Italy), pp. 1-8, 16-18 Oct. 2012.

[7] A.Tani, M.Mengoni, L. Zarri, G.Serra, D.Casadei, "Control of multiphase induction motors with an odd number of phases under open circuit faults", IEEE Trans. on Power Electronics, vol. 27, no. 2, pp. 565-577, 2012

[8] W. Cao, B.C. Mecrow, G.J. Atkinson, J.W. Bennett, D.J. Atkinson, "Overview of electric motor technologies used for More-Electric Aircraft (MEA)", IEEE Trans. on Ind. Electron., vol. 59, no. 9, pp. 3523-3531, Sept. 2012.

[9] F. Scuiller, J.F. Charpentier, E. Semail, "Multi-star multi-phase winding for a high power naval propulsion machine with low ripple torques and high fault tolerant ability," Proc. of Vehicle Power and Propulsion Conference, Lille, France, pp. 1-5, 1-3 Sept. 2010.

[10] L. G. Franquelo, J. Rodriguez, J. I. Leon, S. Kouro, R. Portillo and M. M. Prats, "The age of multilevel converters arrives," IEEE Ind. Electron. Magazine, vol. 2, no. 2, pp. 28-39, June 2008.

[11] S. Yang, A. Bryant, P. Mawby, D. Xiang, Li Ran, P. Tavner, "An industry-based survey of reliability in power electronic converters," IEEE Trans. on Ind. Electron., vol. 47, no. 3, pp. 1441-1451, MayJune 2011

[12] Frede Blaabjerg, M.M.Pecht, "Robust Design and Reliability of Power Electronics", IEEE Trans. on Power Electron., vol. 30, no. 5, pp. 2373-2374, 2015

[13] P.Sanjeevikumar, Frede Blaabjerg, Patrick Wheeler, Olorunfemi Ojo, "Three-phase multilevel inverter configuration for open-winding high power application", Conf. Proc., The 6th IEEE Intl. Symp. on Power Electron. for Distributed Generation Systems, IEEE-PEDG'15, Aachen (Germany), 22-25 June 2015. 